\title{
FONTES, DOSES E MODOS DE APLICAÇÃO DE FÓSFORO NA INTERAÇÃO FÓSFORO-ZINCO EM MILHO
}

\author{
Sources, dosages and manners of phosphorous application on phosphorous-zinc \\ interaction in corn
}

\author{
Leandro Flávio Carneiro 1 , Antônio Eduardo Furtini Neto², Álvaro Vilela de Resende ${ }^{3}$, Nilton Curi ${ }^{4}$, \\ José Zilton Lopes Santos ${ }^{5}$, Fabiano José do Lago ${ }^{6}$
}

\begin{abstract}
RESUMO
No presente trabalho, objetivou-se avaliar a interação P-Zn no milho durante dois cultivos sucessivos, num Argissolo Vermelho típico, textura argilosa, na região do Cerrado. O delineamento experimental foi o de blocos casualizados com quatro repetições, num esquema fatorial $3 \times 2 \times 2+1$, envolvendo três doses de $\mathrm{P}_{2} \mathrm{O}_{5}\left(180,360\right.$ e $\left.540 \mathrm{~kg} \mathrm{ha}^{-1}\right)$, duas fontes (superfosfato triplo - ST e fosfato natural reativo de Arad - FR), duas formas de aplicação (a lanço em área total e no sulco de plantio) e uma testemunha (sem P) como tratamento adicional. Determinaram-se o peso de matéria seca da parte aérea e de grãos, teores de P, Zn e relação P-Zn nas folhas e nos grãos. Os teores de Zn diminuíram com aplicação de ST no sulco, alcançando valores tidos como deficientes, no primeiro cultivo, sem contudo, afetar a produtividade do milho. Os teores de $\mathrm{P}, \mathrm{Zn}$ e relação P-Zn nos grãos apresentaram-se dentro dos padrões adequados para o milho. A interação P-Zn nos tratamentos com ST no sulco de semeadura, talvez pela adubação prévia com Zn, não foi suficiente para afetar o rendimento de grãos do milho.
\end{abstract}

Termos para indexação: Nutrição mineral, adubação fosfatada, avaliação nutricional, Zea mays L.

\section{ABSTRACT}

In the present work, the objective was to evaluate the interaction of P-Zn in corn during two successive cultivations, in a typical Red Argisol, loamy texture, in the area of the Savannah. The experimental layout was the one randomized blocks with four replications, in a $3 \times 2 \times 2+1$ factorial outline, involving three doses of $\mathrm{P}_{2} \mathrm{O}_{5}\left(180,360\right.$ and $\left.540 \mathrm{~kg} \mathrm{ha}^{-1}\right)$, two sources (triple superphosphateST and Arad phosphate rock - FR), two application manners (casting on the total area and in the planting furrow, both in the first year) and a control (without $\mathrm{P}$ ) as an additional treatment. One determined the dry matter weight of the aerial part and of grains, levels of $\mathrm{P}, \mathrm{Zn}$ and the relationship of P/Zn in the leaves and in the grains. The tenors of $\mathrm{Zn}$ were decreased with application of ST in the seed furrow, reaching values said as deficient, in the first cultivation, without affecting, however, the corn produtivety. The tenors of $\mathrm{P}, \mathrm{Zn}$ and $\mathrm{P} / \mathrm{Zn}$ relationship in the grains presented themselves within the normal standard for corn. The interaction P-Zn at treatments with ST in the planting furrow, maybe due to previous manuring of $\mathrm{Zn}$, was not sufficient to affect the yield grain of the corn.

Termos para indexação: Mineral nutrition, phosphorus fertilization, nutritional evaluation, Zea mays L.

(Recebido em 5 de setembro de 2006 e aprovado em 22 de março de 2007)

\section{INTRODUÇÃO}

A interação P-Zn constitui um exemplo clássico da interferência de um elemento sobre o outro, a qual é conhecida na literatura como "deficiência de $\mathrm{Zn}$ induzida pelo fósforo". Uma elevada disponibilidade de P pode induzir deficiência de $\mathrm{Zn}$, que pode ser prevenida ou corrigida pelo fornecimento do micronutriente (OLSEN, 1972).
Existe muita controvérsia quando se discute a interação P-Zn. Diversos autores afirmam que os problemas gerados pela interação ocorrem no solo, outros, porém relatam que a interação ocorre na planta em função do efeito de diluição ou interferência do $\mathrm{P}$ na absorção, translocação e utilização do Zn pela planta (LONERAGAN et al., 1979; OLSEN, 1972).

Uma hipótese relacionada à interação $\mathrm{P}-\mathrm{Zn}$ no solo é a formação de precipitados na forma de $\mathrm{Zn}_{3}\left(\mathrm{PO}_{4}\right)_{2}$, porém

'Engenheiro Agrônomo, Doutorando em Ciência do Solo - Departamento de Ciência do Solo - Universidade Federal de Lavras/UFLA - Cx. P. 3037 37200-000 - Lavras, MG - leoflacar@yahoo.com.br

${ }^{2}$ Doutor em Ciência do Solo, Professor - Departamento de Ciência do Solo - Universidade Federal de Lavras/UFLA - Cx. P. 3037 - $37200-000$ - Lavras, MG - afurtini@ufla.br - Bolsista CNPq

${ }^{3}$ Engenheiro Agrônomo, Doutor, Pesquisador da Embrapa Cerrados/CPAC-Br 020, Km 18 - Cx. P. 08223-73310-970-Planaltina, DF-alvaro@cpac.embrapa.br ${ }^{4}$ Ph. D. em Ciência do Solo, Professor - Departamento de Ciência do Solo - Universidade Federal de Lavras/UFLA - Cx. P. 3037 - $37200-000$ - Lavras, MG - niltcuri@ufla.br

${ }^{5}$ Mestre em Ciência do Solo - Rua Frei Rogato, 5 - Alto Mercado - 39600-000 - Araçuaí, MG - santosilton@yahoo.com.br

${ }^{6}$ Mestre em Solos e Nutrição de Plantas - Rua Conselheiro Joaquim Caetano, 76 - Nova Granada - 30460-500 - Belo Horizonte, MG -fablago11@yahoo.com.br 
essa hipótese parece ser inconsistente, pois esse composto é considerado fonte de $\mathrm{Zn}$ para as plantas, por causa da alta solubilidade (LINDSAY, 1972).

$A$ adição de $P$ pode promover aumento da taxa de crescimento suficiente para diminuir a concentração de $\mathrm{Zn}$ nas plantas ao nível de deficiência, pois a taxa de absorção de zinco não aumenta de forma rápida o suficiente para manter a concentração necessária na parte aérea, caracterizando o efeito de diluição (LONERAGAN \& WEBB, 1993; OLSEN, 1972).

Em relação à absorção, segundo Malavolta et al. (1997), pode haver insolubilização do $\mathrm{Zn}$ pelo fosfato na superfície das raízes (reduzindo a absorção), ou inibição não competitiva da absorção de Zn pelo $P$.

A distribuição do $\mathrm{Zn}$ da raiz para a parte aérea das plantas em altos níveis de fósforo, parece está relacionado com a redução na esterificação de metil em ácido poligalacturônico, aumentando o número de cargas negativas nas raízes, implicando numa menor disponibilidade de zinco para suprir a parte aérea (YOUNGDAHL et al., 1977).

Outros trabalhos referem-se a processos metabólicos, onde o comportamento do $\mathrm{P}$ e do $\mathrm{Zn}$ na planta mudam em função da disponibilidade dos mesmos no meio. Entre o $\mathrm{P}$ e o $\mathrm{Zn}$ parece existir um antagonismo mútuo toda vez que ambos os nutrientes excedem seus valores críticos, mas, o efeito da aplicação de P na deficiência do zinco tem sido aliviado pela adição de uma pequena quantidade do micronutriente (LONERAGAN et al., 1982; OLSEN, 1972).

Portanto, pode-se pressupor que a interação entre fósforo e zinco seja importante para o manejo da adubação de solos tropicais, onde é bastante comum a utilização de altas doses de fósforo, em solos com baixa disponibilidade natural de fósforo e zinco. Nesse contexto, objetivou-se no presente trabalho, avaliar a interação P-Zn, na cultura do milho, em função de fontes, doses e modos de aplicação de fósforo em dois cultivos consecutivos.

\section{MATERIAL E MÉTODOS}

A área experimental apresenta Argissolo Vermelho típico, textura argilosa, fase Cerrado, situado no município de Itumirim-MG. Antes da implantação do experimento, servia ao pastejo bovino, permanecendo coberta por capim braquiária (Brachiaria brizantha (Hochst) Stapf). Os atributos químicos e físicos do solo, previamente à instalação do experimento são expressos na Tabela 1.

Um experimento para avaliar fontes, doses e modos de aplicação de $\mathrm{P}$ para o milho foi instalado em delineamento de blocos casualizados, com quatro repetições. Os tratamentos consistiram de um fatorial $3 \times 2 \times 2+1$, combinando três doses de fósforo $\left(180,360\right.$ e $540 \mathrm{~kg} \mathrm{ha}^{-1}$ de $\mathrm{P}_{2} \mathrm{O}_{5}$ ), dois modos de aplicação (a lanço, sendo distribuídos manualmente em toda área da parcela experimental e incorporados, com enxada, a cerca de $10 \mathrm{~cm}$ de profundidade e localizada, no fundo do sulco de plantio), duas fontes de $\mathrm{P}$ (superfosfato triplo (ST) e fosfato reativo de Arad (FR)) e uma testemunha sem fornecimento de fósforo (tratamento adicional).

Foram conduzidos dois cultivos consecutivos de milho em condições de sequeiro, nos anos agrícolas 2000/ 2001 e 2001/2002, utilizando-se, respectivamente, os híbridos triplos HT 9710-11 e HT 7105-3, desenvolvidos pela Embrapa Milho e Sorgo. Para fins de avaliação, foi considerada uma área útil central de $10,8 \mathrm{~m}^{2}$, com três linhas de seis metros de comprimento, espaçadas de 0,9 metros entre si. A quantidade a aplicar de cada fonte foi calculada com base no teor de $\mathrm{P}_{2} \mathrm{O}_{5}$ total dos fertilizantes. A adubação fosfatada foi realizada apenas no primeiro cultivo, aplicada toda no plantio.

Tabela 1 - Principais atributos químicos e físicos do solo $(0-20 \mathrm{~cm}$ de profundidade $)$ antes da aplicação dos tratamentos.

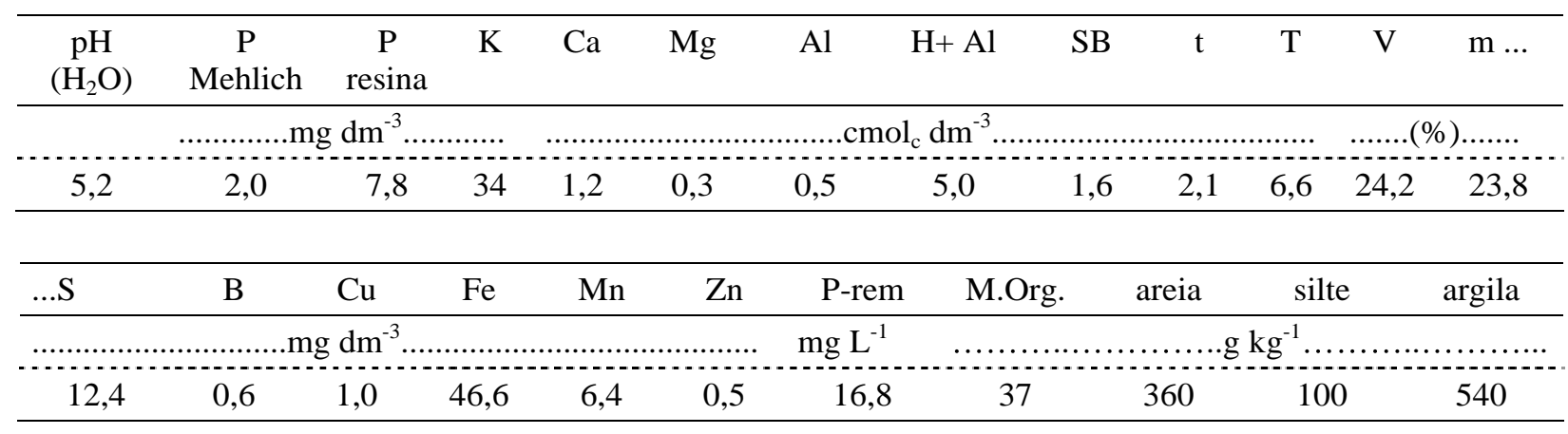

$\mathrm{K}=$ extrator Mehlich 1; Ca, $\mathrm{Mg}$ e $\mathrm{Al}=$ extração com $\mathrm{KCl} \mathrm{mol} \mathrm{L}^{-1} ; \mathrm{Cu}, \mathrm{Fe}, \mathrm{Mn}$ e $\mathrm{Zn}=$ extrator DTPA; B = extração em água quente. Metodologias descritas em Embrapa (1999). Análises realizadas nos laboratórios do Departamento de Ciência do Solo da UFLA. 
No primeiro ano, previamente ao preparo do solo, as áreas receberam calcário dolomítico $\left(1,5 \mathrm{t} \mathrm{ha}^{-1}, \mathrm{PRNT}=\right.$ $100 \%)$. O preparo do solo foi realizado apenas na primeira safra. Após a primeira colheita, os restos culturais foram removidos das parcelas, deixando-se o solo em pousio. Para o segundo cultivo, os sulcos de semeadura foram abertos, seguindo sua localização original. Na Tabela 2, são descritas as datas de plantio e as adubações relativas a cada cultivo.

$\mathrm{Na}$ Figura 1, apresentam-se os dados pluviométricos referentes aos períodos de condução do experimento. De modo geral, as condições climáticas durante o segundo cultivo foram bem mais favoráveis à cultura, com maior quantidade de chuva e distribuição mais regular.
Obteve-se o peso de grãos, matéria seca da parte aérea, teores de $\mathrm{P}, \mathrm{Zn}$ e $\mathrm{P} / \mathrm{Zn}$ nas folhas (primeira folha oposta e abaixo da espiga) e nos grãos para a avaliação da interação P-Zn no milho. Os dados experimentais foram submetidos a análises de variância, teste de média e contraste, com auxílio do programa estatístico Sisvar (FERREIRA, 2000).

\section{RESULTADOS E DISCUSSÃO}

\section{Primeiro cultivo}

Para a matéria seca de plantas (MSP), não houve diferença entre os tratamentos, porém para a produção de grãos houve interação dos fatores fontes x modos de aplicação. Observa-se que aplicação de FR no sulco de

Tabela 2 - Datas de semeadura e adubações de plantio e de cobertura dos dois cultivos de milho.

\begin{tabular}{|c|c|c|c|c|c|c|c|}
\hline \multirow{2}{*}{$\begin{array}{l}\text { Ano } \\
\text { agrícola }\end{array}$} & \multirow{2}{*}{$\begin{array}{l}\text { Data de } \\
\text { plantio }\end{array}$} & \multicolumn{4}{|c|}{$\begin{array}{l}\text { Adubação de plantio } \\
\left(\mathrm{kg} \mathrm{ha}^{-1}\right)\end{array}$} & \multicolumn{2}{|c|}{$\begin{array}{l}\text { Adubação de cobertura } \\
\left(\mathrm{kg} \mathrm{ha}^{-1}\right)\end{array}$} \\
\hline & & $\mathrm{N}$ & $\mathrm{K}_{2} \mathrm{O}$ & $S$ & $\mathrm{Zn}$ & $\mathrm{N}$ & $\mathrm{K}_{2} \mathrm{O}$ \\
\hline 2000/01 & $25 / 11 / 00$ & $21^{\mathrm{a}}$ & $90^{\mathrm{b}}$ & $24^{\mathrm{a}}$ & $2,0^{\mathrm{c}}$ & $56^{\mathrm{d}} \times 3$ & $3^{d} \times 3$ \\
\hline $2001 / 02$ & $20 / 11 / 01$ & $21^{\mathrm{a}}$ & $90^{\mathrm{b}}$ & $24^{\mathrm{a}}$ & $2,0^{\mathrm{c}}$ & $78^{d} \times 2$ & $4^{\mathrm{d}} \times 2$ \\
\hline
\end{tabular}

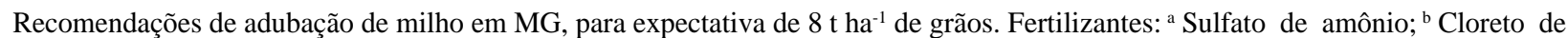
potássio; ${ }^{\mathrm{c}}$ sulfato de zinco; ${ }^{\mathrm{d}}$ Uréia + Cloreto de Potássio. Adubação de cobertura foi parcelada em 3 e 2 vezes em 2000 e 2001, respectivamente.
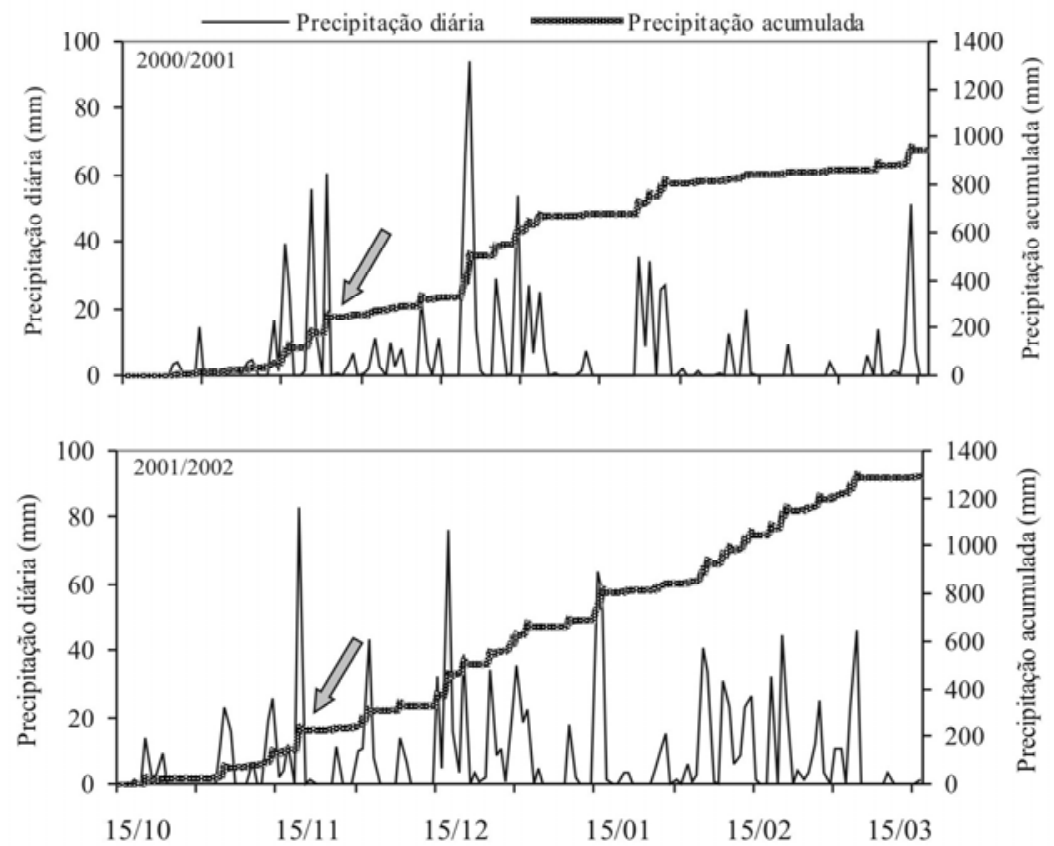

Figura 1 - Dados pluviométricos referentes aos períodos de condução dos dois cultivos de milho (as setas indicam época da semeadura). 
plantio proporcionou menor produção de grãos quando comparado com o ST. Já para aplicação a lanço não houve diferença entre as fontes de fósforo (Tabela 3).

Os teores de $\mathrm{P}$ nas folhas do milho foram em média maiores com o uso do ST em relação ao FR (Tabela 4) e a aplicação das fontes no sulco de plantio proporcionou maior concentração de $\mathrm{P}\left(2,6 \mathrm{~g} \mathrm{~kg}^{-1}\right)$, em comparação com a aplicação a lanço $\left(2,4 \mathrm{~g} \mathrm{~kg}^{-1}\right)$.

Houve interação dos fatores fontes $x$ modos de aplicação para os teores de Zn e para a relação $\mathrm{P} / \mathrm{Zn}$ nas folhas do milho, onde a aplicação de ST, principalmente no sulco de semeadura, proporcionou menores teores de $\mathrm{Zn}$ e maior relação $\mathrm{P} / \mathrm{Zn}$, quando comparado com o FR (Tabela 4).

Nos teores de $\mathrm{P}$ e na relação $\mathrm{P} / \mathrm{Zn}$ nos grãos houve interação dos fatores fontes $\mathrm{x}$ doses $\mathrm{x}$ modos de aplicação de P. Já para os teores de Zn nos grãos, houve efeito isolado de fontes de fósforo, sendo em média menores com a aplicação de ST em relação ao FR (Tabela 5).

\section{Segundo cultivo}

Não houve diferença entre os tratamentos tanto para o peso de plantas quanto para o peso de grãos (Tabela 6).
Houve interação dos fatores fontes $\mathrm{x}$ modos de aplicação para os teores de fósforo e relação $\mathrm{P} / \mathrm{Zn}$ nas folhas do milho. Essas variáveis apresentaram menores valores, quando aplicou-se o FR no sulco de semeadura, em relação ao ST (Tabela 7). Para os teores de Zn nas folhas, houve efeito isolado de modos de aplicação, os quais foram menores com a aplicação no sulco de plantio $\left(20 \mathrm{mg} \mathrm{kg}^{-1}\right)$ em relação à aplicação a lanço $\left(23,6 \mathrm{mg} \mathrm{kg}^{-1}\right)$ (Tabela 7). É importante ressaltar que os teores de $\mathrm{Zn}$ nas folhas encontram-se na faixa adequada para o milho (MARTINEZ et al., 1999), diferentemente do primeiro ano com as aplicações de ST no sulco de plantio (Tabela 4).

O nivelamento dos efeitos dos tratamentos para MSP no primeiro ano, pode está relacionado com a deficiência hídrica em certos períodos do cultivo (Figura 1). A umidade do solo é um fator preponderante para que ocorram a solubilização e a difusão do fósforo no solo, eventos decisivos para que haja resposta das plantas à aplicação de adubos fosfatados (MALAVOLTA et al., 1997). Lopes (1999) relata que a solubilidade dos fosfatos naturais é aumentada com a acidez dos solos, portanto, quando incorporados no solo, o contato é favorecido, aumentando a solubilização do fosfato, o que poderia explicar a menor produção de grãos com o FR no sulco (Tabela 3).

Tabela 3 - Matéria seca da parte aérea e peso de grãos do milho em função de fontes, doses e modos de aplicação de fósforo (Safra 2000/01).

\begin{tabular}{|c|c|c|c|c|c|c|}
\hline \multirow{3}{*}{ Doses de P } & \multicolumn{3}{|c|}{ Matéria seca $\left(\mathrm{kg} \mathrm{ha}^{-1}\right)$} & \multicolumn{3}{|c|}{ Peso de grãos $\left(\mathrm{kg} \mathrm{ha}^{-1}\right)$} \\
\hline & \multicolumn{3}{|c|}{ Modos de aplicação } & \multicolumn{3}{|c|}{ Modos de aplicação } \\
\hline & Lanço & Sulco & Média & Lanço & Sulco & Média \\
\hline \multicolumn{7}{|c|}{ Superfosfato Triplo... } \\
\hline 180 & 4.167 & 4.980 & 4.572 & 4.281 & 4.313 & 4.297 \\
\hline 360 & 4.167 & 5.440 & 4.803 & 4.014 & 5.210 & 4.612 \\
\hline 540 & 5.301 & 5.417 & 5.359 & 4.156 & 4.644 & 4.400 \\
\hline Média & 4.545 & 5.278 & 4.911 & $4.150 \mathrm{a} \mathrm{A}$ & $4.722 \mathrm{a} \mathrm{A}$ & 4.436 \\
\hline \multicolumn{7}{|c|}{ 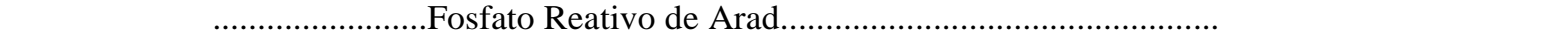 } \\
\hline 180 & 4.468 & 4.259 & 4.363 & 3.731 & 3.190 & 3.460 \\
\hline 360 & 4.954 & 4.630 & 4.792 & 4.030 & 3.652 & 3.841 \\
\hline 540 & 4.537 & 3.935 & 4.236 & 4.250 & 3.211 & 3.731 \\
\hline Média & 4.653 & 4.275 & 4.464 & 4.003 a $\mathrm{A}$ & $3.351 \mathrm{a} \mathrm{B}$ & 3.677 \\
\hline Testemunha & \multicolumn{3}{|c|}{$4.136 \mathrm{~ns}$} & \multicolumn{3}{|c|}{$3.316 \mathrm{~ns}$} \\
\hline C.V. $(\%)$ & \multicolumn{3}{|c|}{23,27} & \multicolumn{3}{|c|}{21,20} \\
\hline
\end{tabular}

Médias seguidas de mesmas letras minúsculas nas linhas ou maiúsculas na coluna não diferem estatisticamente pelo teste de Tukey, a $5 \%$ de probabilidade. $n s=$ média do tratamento-testemunha não difere em relação à média do fatorial $($ Teste $\mathrm{F}, \mathrm{p}<0,05)$. 
Tabela 4 - Teores de fósforo, zinco e relação P/Zn na primeira folha oposta e abaixo da espiga, no florescimento do milho, em função de fontes, doses e modo de aplicação de fósforo (Safra 2000/01).

\begin{tabular}{|c|c|c|c|c|c|c|c|c|c|}
\hline \multirow{3}{*}{$\begin{array}{l}\text { Doses de } \\
\mathrm{P}_{2} \mathrm{O}_{5}\end{array}$} & \multicolumn{3}{|c|}{ Fósforo (g.kg-1) } & \multicolumn{3}{|c|}{ Zinco $\left(\mathrm{mg} \cdot \mathrm{kg}^{-1}\right)$} & \multicolumn{3}{|c|}{ Relação P/Zn } \\
\hline & \multicolumn{3}{|c|}{ Modo de aplicação } & \multicolumn{3}{|c|}{ Modo de aplicação } & \multicolumn{3}{|c|}{ Modo de aplicação } \\
\hline & Lanço & Sulco & Média & Lanço & Sulco & Média & Lanço & Sulco & Média \\
\hline & \multicolumn{9}{|c|}{..Superfosfato Triplo.. } \\
\hline 180 & 2,2 & 2,2 & 2,2 & 22 & 14 & 18 & 100 & 156 & 128 \\
\hline 360 & 2,5 & 2,6 & 2,5 & 20 & 13 & 16 & 128 & 198 & 163 \\
\hline 540 & 2,6 & 2,9 & 2,8 & 21 & 13 & 16 & 129 & 241 & 185 \\
\hline \multirow[t]{2}{*}{ Média } & 2,5 & 2,6 & $2,5 \mathrm{~A}$ & $21 \mathrm{a} \mathrm{B}$ & $14 \mathrm{~b} \mathrm{~B}$ & 17 & $119 \mathrm{~b} \mathrm{~A}$ & 198 a A & 159 \\
\hline & \multicolumn{9}{|c|}{.Fosfato Reativo de Arad.. } \\
\hline 180 & 2,0 & 2,1 & 2,0 & 24 & 29 & 27 & 87 & 74 & 80 \\
\hline 360 & 2,3 & 2,7 & 2,5 & 31 & 29 & 30 & 76 & 95 & 86 \\
\hline 540 & 2,6 & 2,6 & 2,6 & 27 & 27 & 27 & 98 & 99 & 98 \\
\hline Média & 2,3 & 2,5 & $2,3 \mathrm{~B}$ & 27 a A & 28 a A & 28 & 87 a B & 89 a B & 88 \\
\hline Testemunha & \multicolumn{3}{|c|}{$1,6 *$} & \multicolumn{3}{|c|}{$33 *$} & \multicolumn{3}{|c|}{$50 *$} \\
\hline C.V. (\%) & \multicolumn{3}{|c|}{9,22} & \multicolumn{3}{|c|}{14,67} & \multicolumn{3}{|c|}{15,65} \\
\hline
\end{tabular}

Médias seguidas de mesmas letras minúsculas nas linhas ou maiúsculas na coluna não diferem estatisticamente pelo teste de Tukey, a 5\% de probabilidade. * = média do tratamento-testemunha difere em relação à média do fatorial $($ Teste $\mathrm{F}, \mathrm{p}<0,05)$.

Tabela 5 - Teores de fósforo, zinco e relação P/Zn nos grãos de milho em função de fontes, doses e modo de aplicação de fósforo (Safra 2000/01).

\begin{tabular}{|c|c|c|c|c|c|c|c|c|c|}
\hline \multirow{4}{*}{$\begin{array}{l}\text { Doses de } \\
\mathrm{P}_{2} \mathrm{O}_{5}\end{array}$} & \multirow{2}{*}{\multicolumn{3}{|c|}{$\frac{\text { Fósforo }\left(\mathrm{g} \cdot \mathrm{kg}^{-1}\right)}{\text { Modo de aplicação }}$}} & \multirow{2}{*}{\multicolumn{3}{|c|}{$\frac{\text { Zinco }\left(\mathrm{mg} \mathrm{kg}^{-1}\right)}{\text { Modo de aplicação }}$}} & \multirow{2}{*}{\multicolumn{3}{|c|}{$\frac{\text { Relação P/Zn }}{\text { Modo de aplicação }}$}} \\
\hline & & & & & & & & & \\
\hline & Lanço & Sulco & Média & Lanço & Sulco & Média & Lanço & Sulco & Média \\
\hline & \multicolumn{9}{|c|}{ 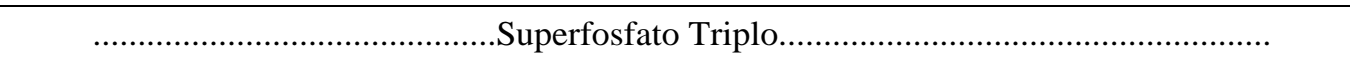 } \\
\hline 180 & 4,9 & 3,5 & 4,2 & 32 & 36 & 34 & 152 & 98 & 125 \\
\hline 360 & 3,7 & 4,2 & 4,0 & 26 & 35 & 31 & 145 & 120 & 133 \\
\hline 540 & 3,7 & 4,6 & 4,2 & 35 & 37 & 36 & 108 & 126 & 117 \\
\hline \multirow[t]{2}{*}{ Média } & 4,1 & 4,1 & 4,1 & 31 & 36 & $34 \mathrm{~B}$ & 135 & 115 & 125 \\
\hline & \multicolumn{9}{|c|}{ Fosfato Reativo de Arad.................................................. } \\
\hline 180 & 4,2 & 5,2 & 4,7 & 39 & 38 & 39 & 106 & 137 & 122 \\
\hline 360 & 3,8 & 3,9 & 3,9 & 38 & 37 & 38 & 98 & 112 & 105 \\
\hline 540 & 3,6 & 4,5 & 4,0 & 39 & 42 & 41 & 94 & 106 & 100 \\
\hline Média & 3,9 & 4,5 & 4,2 & 39 & 39 & $39 \mathrm{~A}$ & 99 & 118 & 109 \\
\hline Testemunha & \multicolumn{3}{|c|}{$3,9 \mathrm{~ns}$} & \multicolumn{3}{|c|}{$43 *$} & \multicolumn{3}{|c|}{$92 *$} \\
\hline C.V. (\%) & \multicolumn{3}{|c|}{14,65} & \multicolumn{3}{|c|}{14,48} & \multicolumn{3}{|c|}{15,54} \\
\hline
\end{tabular}

Médias seguidas de mesma letra maiúsculas na coluna não diferem estatisticamente pelo teste de Tukey, a 5\% de probabilidade. * e ns = média do tratamento-testemunha difere e não difere, respectivamente, em relação à média do fatorial $($ Teste $F, p<0,05)$. 
O efeito residual da adubação fosfatada parece ter sido suficiente para atender às necessidades nutricionais do milho no segundo cultivo, favorecido pela melhor oferta e regularidade de chuvas (Figura 1), pois não houve diferença entre os tratamentos para matéria seca e peso de grãos (Tabela 6).

Os resultados obtidos para $\mathrm{P}$ foliar ficaram dentro da faixa de referência para o milho $\left(2,5-3,5 \mathrm{~g} \mathrm{~kg}^{-1}\right)$, segundo Martinez et al. (1999), exceto para o tratamento testemunha e para o FR no sulco, no segundo cultivo (Tabela 7). Porém, Oliveira (2002) relata níveis críticos de $\mathrm{P}$ nas folhas de $1,8 \mathrm{~g} \mathrm{~kg}^{-1}$ para o milho cultivado em solos de Cerrado, próximo ao encontrado para o FR no sulco, o que ajuda a explicar a ausência de efeitos entre os tratamentos para MSP e produção de grãos no segundo cultivo (Tabela 6).

No caso dos teores foliares de $\mathrm{Zn}$, os únicos tratamentos que apresentaram teores abaixo do valor de referência (20 mg kg $\mathrm{mg}^{-1}$, segundo Malavolta et al. (1997) e Martinez (1999), foram os que receberam ST no sulco, no primeiro ano (Tabela 4). Porém, Couto et al. (1992), combinando diferentes doses de $\mathrm{Zn}$ e solos, observaram níveis críticos entre 15,9 - 19,5 $\mathrm{mg} \mathrm{kg}^{-1}$, para a cultura do milho. Ainda Korndorfer (1999), em milho, aplicando 400 $\mathrm{kg} \mathrm{ha}^{-1}$ de $\mathrm{P}_{2} \mathrm{O}_{5}$, usando o ST, também observaram redução nos teores de $\mathrm{Zn}$ nas folhas (13 $\mathrm{mg} \mathrm{kg}^{-1}$ ), sem, contudo comprovar queda de produtividade.

A redução do teor foliar de $\mathrm{Zn}$ não poderia ser explicada pelo o efeito de diluição (JARREL \& BEVERLY, 1981), uma vez que não houve maior influência dos tratamentos na produção de MSP do milho (Tabela 3). Um princípio bem conhecido, no caso do $\mathrm{Zn}$, é que as exigências das raízes são atendidas primeiro e depois ocorre um significativo transporte para a parte aérea (OLSEN, 1972). Essa hipótese, aliada a uma possível insolubilização do $\mathrm{Zn}$ pelo fosfato na superfície das raízes (reduzindo a absorção), ou inibição não competitiva da absorção de Zn pelo P (MALAVOLTA et al., 1997) poderiam explicar os baixos teores de $\mathrm{Zn}$ nas folhas, nas quais haveria deficiência temporária de $\mathrm{Zn}$, sem contudo afetar a produtividade do milho (Tabela 3).

Segundo Sumner \& Farina (1986), valores da relação $\mathrm{P} / \mathrm{Zn}$ nas folhas em torno de 100, para o milho, representam uma condição de equilíbrio entre o $\mathrm{P}$ e o Zn, refletindo em maiores produções. Para os tratamentos, com a aplicação de ST no sulco, no primeiro cultivo, a relação $\mathrm{P} / \mathrm{Zn}$ atingiu valores acima de 200 (Tabela 4), o que, teoricamente, deveria limitar o desenvolvimento do milho e a própria absorção de $\mathrm{P}$, o que não foi observado no presente estudo. Porém, Stukenholts et al. (1966) estudando a interação P-Zn na

Tabela 6 - Matéria seca da parte aérea e peso de grãos do milho em função de fontes, doses e modos de aplicação de fósforo (Safra 2001/02).

\begin{tabular}{|c|c|c|c|c|c|c|}
\hline \multirow{3}{*}{ Doses de $\mathrm{P}$} & \multicolumn{3}{|c|}{ Matéria seca $\left(\mathrm{kg} \cdot \mathrm{ha}^{-1}\right)$} & \multicolumn{3}{|c|}{ Peso de grãos (kg.há $\left.{ }^{-1}\right)$} \\
\hline & \multicolumn{3}{|c|}{ Modos de aplicação } & \multicolumn{3}{|c|}{ Modos de aplicação } \\
\hline & Lanço & Sulco & Média & Lanço & Sulco & Média \\
\hline & \multicolumn{6}{|c|}{ 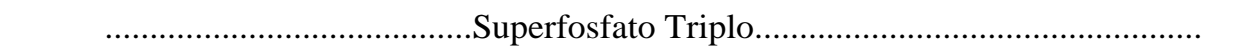 } \\
\hline 180 & 8.395 & 7.901 & 8.148 & 7.883 & 8.059 & 7.971 \\
\hline 360 & 7.176 & 9.560 & 8.368 & 7.463 & 9.185 & 8.324 \\
\hline 540 & 7.731 & 7.940 & 7.836 & 7.759 & 8.431 & 8.095 \\
\hline \multirow[t]{2}{*}{ Média } & 7.767 & 8.467 & 8.117 & 7.702 & 8.558 & 8.130 \\
\hline & \multicolumn{6}{|c|}{ 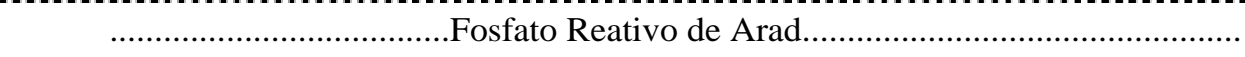 } \\
\hline 180 & 6.204 & 7.176 & 6.690 & 7.444 & 7.574 & 7.509 \\
\hline 360 & 9.884 & 7.755 & 8.819 & 9.613 & 7.535 & 8.574 \\
\hline 540 & 7.685 & 8.333 & 8.009 & 8.264 & 8.049 & 8.156 \\
\hline Média & 7.924 & 7.755 & 7.840 & 8.441 & 7.719 & 8.080 \\
\hline Testemunha & \multicolumn{3}{|c|}{$4.290 *$} & \multicolumn{3}{|c|}{$5.268 *$} \\
\hline C.V. (\%) & \multicolumn{3}{|c|}{30,99} & \multicolumn{3}{|c|}{14,10} \\
\hline
\end{tabular}

* = média do tratamento-testemunha difere em relação à média do fatorial (Teste $\mathrm{F}, \mathrm{p}<0,05)$. 
Tabela 7 - Teores de fósforo, zinco e relação P/Zn na primeira folha oposta e abaixo da espiga, no florescimento do milho, em função de fontes, doses e modo de aplicação de fósforo (Safra 2001/02).

\begin{tabular}{|c|c|c|c|c|c|c|c|c|c|}
\hline \multirow{3}{*}{$\begin{array}{l}\text { Doses de } \\
\mathrm{P}_{2} \mathrm{O}_{5}\end{array}$} & \multirow{2}{*}{\multicolumn{3}{|c|}{$\begin{array}{c}\left.\text { Fósforo (g.ha }{ }^{-1}\right) \\
\text { Modo de aplicação }\end{array}$}} & \multirow{2}{*}{\multicolumn{3}{|c|}{$\begin{array}{c}\left.\text { Zinco (mg.há }{ }^{-1}\right) \\
\text { Modo de aplicação }\end{array}$}} & \multirow{2}{*}{\multicolumn{3}{|c|}{$\frac{\text { Relação P/Zn }}{\text { Modo de aplicação }}$}} \\
\hline & & & & & & & & & \\
\hline & Lanço & Sulco & Média & Lanço & Sulco & Média & Lanço & Sulco & Média \\
\hline & \multicolumn{9}{|c|}{ 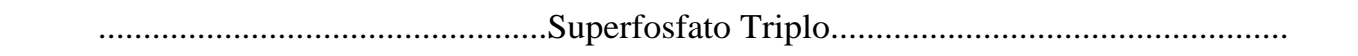 } \\
\hline 180 & 2,0 & 2,4 & 2,2 & 22 & 24 & 23 & 89 & 100 & 94 \\
\hline 360 & 2,4 & 2,5 & 2,5 & 25 & 19 & 22 & 101 & 129 & 115 \\
\hline 540 & 2,4 & 2,8 & 2,6 & 24 & 21 & 22 & 103 & 134 & 119 \\
\hline \multirow[t]{2}{*}{ Média } & $2,3 \mathrm{~b} \mathrm{~A}$ & 2,6 a A & 2,4 & 24 & 22 & 23 & $97 \mathrm{~b} \mathrm{~A}$ & 121 a A & 109 \\
\hline & \multicolumn{9}{|c|}{ 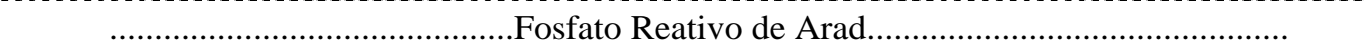 } \\
\hline 180 & 2,2 & 1,5 & 1,9 & 22 & 20 & 21 & 98 & 78 & 88 \\
\hline 360 & 2,4 & 1,7 & 2,1 & 26 & 19 & 23 & 95 & 91 & 93 \\
\hline 540 & 2,5 & 1,9 & 2,2 & 22 & 19 & 21 & 110 & 104 & 107 \\
\hline Média & 2,4 a A & $1,7 \mathrm{~b} \mathrm{~B}$ & 2,1 & 24 & 19 & 21 & $101 \mathrm{a} \mathrm{A}$ & 91 a B & 96 \\
\hline Testemunha & \multicolumn{3}{|c|}{$1,6 *$} & \multicolumn{3}{|c|}{$25 \mathrm{~ns}$} & \multicolumn{3}{|c|}{$65 *$} \\
\hline C.V. (\%) & \multicolumn{3}{|c|}{10,20} & \multicolumn{3}{|c|}{16,18} & \multicolumn{3}{|c|}{12,69} \\
\hline
\end{tabular}

Médias seguidas de mesma letra minúscula na linha e maiúsculas na coluna não diferem estatisticamente pelo teste de Tukey, a 5\% de probabilidade. * e ns = média do tratamento-testemunha difere e não difere, respectivamente, em relação à média do fatorial (Teste $\mathrm{F}, \mathrm{p}<0,05)$.

nutrição do milho observaram em condições de campo e casa de vegetação, nível crítico da relação P/Zn na folha de 350, quando o $\mathrm{Zn}$ foi fornecido. Warnock (1970) observou valores em torno de 743. Portanto, pode-se sugerir que níveis críticos da relação $\mathrm{P} / \mathrm{Zn}$ na folha do milho sejam mais abrangentes, na presença do $\mathrm{Zn}$, do que os citados por Sumner \& Farina (1986).

No segundo cultivo, os efeitos sobre o Zn e na relação $\mathrm{P} / \mathrm{Zn}$ nas folhas foram menores (Tabela 7). Isso pode ter sido em função da extração de $\mathrm{P}$ no primeiro ano, do tempo de contato do $\mathrm{P}$ com o solo, da aplicação de $\mathrm{Zn}$ na adubação de plantio e de melhores condições climáticas.

Segundo Mengel \& Kirkby (1987), para a maioria dos cereais, inclusive para o milho, o teor de $\mathrm{P}$ nos grãos está em torno de 4-5 $\mathrm{g} \mathrm{kg}^{-1}$ e Fornasieri Filho (1992) relata que, em plantas de milho com alta produtividade, o teor de $\mathrm{P}$ nos grãos foi de $3,97 \mathrm{~g} \mathrm{~kg}^{-1}$. Para a relação $\mathrm{P} / \mathrm{Zn}$ nos grãos, Takkar et al. (1976), em campo, observaram que, para valores acima de 245, o excesso de $\mathrm{P}$ induziu deficiência de $\mathrm{Zn}$ no milho. Fornasieri Filho (1992) relata teores adequados para o Zn nos grãos em torno de $28 \mathrm{mg} \mathrm{kg}^{-1}$.

Apesar da interação tripla para os teores de $\mathrm{P} e \mathrm{P} /$ $\mathrm{Zn}$ nos grãos e do menor teor de $\mathrm{Zn}$ nos grãos com o uso de ST, no primeiro cultivo (Tabela 5) e no segundo cultivo (dados não apresentados), os teores de $\mathrm{P}$ e $\mathrm{Zn}$ e a relação $\mathrm{P} / \mathrm{Zn}$ mostraram, de maneira geral, estar dentro dos padrões adequados para o milho, segundo os autores citados acima. Isso indica que, provavelmente, os tratamentos não afetaram a utilização do $\mathrm{Zn}$ e a redistribuição de $\mathrm{P}$ e $\mathrm{Zn}$ nas plantas. Essa observação é reforçada pela ausência de efeito na MSP e produção de grãos (Tabela 3), nos tratamentos (ST no sulco) que apresentaram menores teores de $\mathrm{Zn}$ nas folhas (Tabela 4).

Com base nesses resultados pode-se inferir que, mesmo com a aplicação de altas doses de P com uso de fonte solúvel (ST) no sulco de plantio, com aplicação de zinco, não se observou queda de produtividade em função da interação P-Zn, em solo argiloso da região do cerrado. É importante ressaltar que as doses de $\mathrm{P}$ utilizadas nesse ensaio são muito maiores do que as recomendadas no Brasil. Isso reforça a importância dos resultados do presente trabalho.

\section{CONCLUSÕES}

Os teores foliares de $\mathrm{Zn}$ foram reduzidos nos tratamentos envolvendo a fonte solúvel (ST), em aplicação localizada, principalmente no primeiro ano de cultivo, sem, contudo, afetar a produção de matéria seca e de grãos do milho. 
Os teores de $\mathrm{P}, \mathrm{Zn}$ e relação $\mathrm{P} / \mathrm{Zn}$ nos grãos não seguiram os padrões observados nas folhas, os quais se encontraram dentro dos padrões adequados para o milho. Isso reforça o próprio conceito da interação P-Zn, ou seja, uma elevada disponibilidade de $\mathrm{P}$ pode induzir deficiência de $\mathrm{Zn}$, a qual pode ser prevenida ou corrigida pelo fornecimento do micronutriente.

Os níveis da interação P-Zn observados nos tratamentos envolvendo o ST no sulco de semeadura, talvez pela adubação prévia com Zn, não foram suficientes para afetar o rendimento de grãos do milho.

\section{REFERÊNCIAS BIBLIOGRÁFICAS}

COUTO, C. et al. Níveis crítico de zinco no solo e na planta para o crescimento de milho em amostras de solo com diferentes valores do fator capacidade. Revista Brasileira de Ciência do Solo, Campinas, v. 16, p. 79-87, 1992.

EMPRESA BRASILEIRA DE PESQUISA AGROPECUÁRIA. Embrapa Solos, Embrapa Informática Agropecuária. Manual de análises químicas de solos, plantas e fertilizantes. Brasília, DF, 1999. 370 p.

FERREIRA, D. F. Análises estatísticas por meio do Sisvar para Windows versão 4.0. In: REUNIÃO ANUAL DA REGIÃO BRASILEIRA DA SOCIEDADE INTERNACIONAL DE BIOMETRIA, 2000, São Carlos, SP. Programa e resumos... São Carlos: UFScar, 2000. p. 255-258.

FORNASIERI FILHO, D. A cultura do milho. Jaboticabal: Funep, 1992. 273 p.

JAREEL, W. M.; BEVERLY, R. B. The dilution effect in plant nutrition studies. Advance in Agronomy, New York, v. 34, p. 197-224, 1981.

KORNDORFER, G. H. Eficiência agronômica de fosfatos naturais reativos na cultura do milho. Scientia Agrícola, Piracicaba, v. 56, n. 2, p. 1-9, 1999.

LINDSAY, W. L. Inorganic phase equilibria of micronutrients in soils. In: MORTVEDT, J. J.; GIORDANO, P. M.; LINDSAY, W. L. (Eds.). Micronutrients in agriculture. Madison: Soil Science of America, 1972. p. 41-47.

LONERAGAN, J. F.; GROVE, T. S.; ROBSON, A. D.; SNOWBALL, K. Phosphorus toxicity as a factor in zincphosphorus interactions inplants. Soil Science Society of American Journal, Madison, v. 43, p. 966-972, 1979.
LONERAGAN, J. F.; GRUNER, R. M.; WELCH, E. A.; ADUAYI, A.; LAZAR, V. A.; CARY, E. E. Phosphorus accumulation and toxicity in leaves in relation to zinc supply. Soil Science Societe of American Journal, Madison, v. 46, p. 345-352, 1982.

LONERAGAN, J. F.; WEBB, M. J. Interactions between zinc and other nutrients affecting the growth of plants. In: ROBSON, A. D. (Ed.). Zinc in soil and plants. Madison: Kluwer Academic, 1993. p. 119-134.

LOPES, A. S. Fosfatos naturais. In: RIBEIRO, A. C.; GUIMARÃES, P. T. G.; ALVAREZ, V. H. (Eds.). Recomendações para o uso de corretivos e fertilizantes em Minas Gerais: $5^{a}$ aproximação. Viçosa: CFSEMG, 1999. p. 65-66.

MALAVOLTA, E.; VITTI, G. C.; OLIVEIRA, S. A. Avaliação do estado nutricional das plantas: princípios e aplicações. 2. ed. Piracicaba: Potafos, 1997. 319 p.

MARTINEZ, H. E. P.; CARVALHO, J. G.; SOUZA, R. B. Diagnose foliar. In: COMISSÃO DE FERTILIDADE DO SOLO DO ESTADO DE MINAS GERAIS. Recomendações para o uso de corretivos e fertilizantes em minas Gerais: 5 a aproximação. Viçosa, 1999. p. 143-168.

MENGEL, K.; KIRKBY, A. Principles of plant nutrition. Bern: International Potash Institute, 1987. 687 p.

OLIVEIRA, S. A. Análise foliar. In: SOUSA, D. M. G.; LOBATO, E. (Eds.). Cerrado: correção do solo e adubação. Planaltina: Embrapa Cerrados, 2002. p. 245-256.

OLSEN, S. R. Micronutrients Interactions. In: MORTVEDT, J. J.; GIORDANO, P. M.; LINDSAY, W. L. (Eds.). Micronutrients in agriculture. Madison: Soil Science Society of America, 1972. p. 243-264.

STUKENHOLTZ, D. D.; OLSEN, R. J.; GERALD, G.; OLSON, R. A. On the mechanism of phosphorus-zinc interaction in corn nutrition. Soil Science Society America, Madison, v. 30, p. 759-763, 1966.

SUMNER, M. E.; FARINA, M. P. W. Phosphorus interaction with other nutrients and lime in field cropping systems. Advances in Soil Science, New York, v. 5, p. 201-236, 1986. 
TAKKAR, P. N.; MANN, M. S.; BANSAL, R. L.; RANDHAWA, N. S.; SINGH, H. Yield and uptake response of corn to zinc, as influenced by phosphorus fertilization. Agronomy Journal, Madison, v. 68, n. 6, p. 942-946, Nov./Dec. 1976.

WARNOCK, R. E. Micronutrients uptake and mobility with in corn plants (Zea mays L.) in relation to phosphorus- induced zinc deficiency. Soil Science Society America, Madison, v. 34, p. 765-769, 1970.

YOUNGDAHL, L. J. et al. Changes in the Zinc-65 distribution in corn root tissue with a phosphorus variable. Crop Science, Madison, v. 17, p. 66-69, 1977. 